\title{
La influencia de la joyería y orfebrería tardogótica de la corte de los Reyes Católicos en la Inglaterra Tudor*
}

\author{
Emma Luisa CAHILl MarróN \\ Universidad de Cantabria \\ Departamento de Historia Moderna y Contemporánea \\ cahille@unican.es
}

\begin{abstract}
RESUMEN
La alianza entre Castilla, Aragón e Inglaterra tras el ascenso de la dinastía Tudor al trono de Inglaterra supuso la llegada a la corte inglesa de una suntuosa dote matrimonial para la infanta Catalina de Aragón, que contrajo matrimonio con ambos herederos de Enrique VII, Arturo y Enrique. En contraposición con el reinado de su padre, en diversos inventarios de la época de Enrique VIII abundan las referencias a joyas y piezas de orfebrería con decoraciones de haces de flechas, castillos y granadas o con piezas que se denominan como Spanish work o de estilo español. El objetivo de este artículo es mostrar cómo la orfebrería del reinado de los Reyes Católicos tuvo un impacto en el desarrollo artístico Tudor y cómo los objetos de la dote de la infanta Catalina aparecen no solo en inventarios reales sino que se diseminaron por la corte. También se apuntará a posibles conexiones entre la reina Catalina y su labor como promotora artística en la corte Tudor.
\end{abstract}

Palabras clave: Reyes Católicos, Tudor, Catalina de Aragón, Enrique VIII, orfebrería, joyería.

\section{The Influence of Late Gothic Jewellery and Goldsmithing of the Court of the Catholic Monarchs in Tudor England}

\begin{abstract}
The alliance between Castile, Aragon and England after the rise of the Tudor dynasty to the throne of England meant the arrival to the English court of a sumptuous matrimonial dowry for the infanta Catherine of Aragon, who was married to both of Henry VII's heirs, Arthur and Henry. In contrast to his father's reign, in various inventories in Henry VIII's time there are abundant references to jewels and goldsmith pieces with decorations of sheaths of arrows, castles and pomegranates or pieces that are referred to as Spanish work or of Spanish style. The aim of this paper is to show how goldsmithing in the reign of the Catholic Monarchs had an impact on the Tudor artistic development and how the objects in the dowry of the infanta Catherine appear not only in royal inventories but were spread throughout the court. Possible connections between Queen Catherine and her role as an artistic patron in the Tudor court will also be pointed out.
\end{abstract}

Key words: Catholic Monarchs, Tudor, Catherine of Aragon, Henry VIII, goldsmithing, jewellery.

\footnotetext{
* Este trabajo de investigación ha sido financiado por "Arquitectura Tardogótica en la Corona de Castilla: Trayectorias e Intercambios”, 2012-2014. Ministerio de Ciencia e Innovación, Gobierno de España. Dirección General de Investigación (ref. HAR2011-25138).
} 


\section{La magnificencia de la corte de los Reyes Católicos}

"Era alrededor de las siete en punto de la tarde antes de que los embajadores fueran convocados, y la luz del día se iba yendo, pero fueron llamados con gran acompañamiento de antorchas. Cuando fueron conducidos al palacio donde se hallaban los soberanos los encontraron en una gran estancia sentados bajo un rico dosel ceremonial de paño de oro. Y en medio de esta tela real destacaba un escudo dividido con las armas de Castilla y Aragón. Y el rey lucía una exuberante ropa de hilo de oro, tejida enteramente de oro y festoneada con una rica orla de preciosa marta cebellina; y la reina estaba sentada a su lado, cubierta con un rico traje de la misma ropa tejida de oro que llevaba el rey y confeccionada a la moda del país, tal y como las llevan actualmente las damas del reino. Y sobre dicho traje colgaba una mantilla de terciopelo negro, toda veteada de grandes agujeros, como para mostrar bajo el terciopelo el tejido de oro con que se había vestido. Y sobre dicha manta una tira (de guarnición), no desplegada sino en una especie de ribete [roto], compuesta de partes oblongas de la longitud aproximada de un meñique y de mitad de un dedo de anchura, toda hecha de oro sólido; y cada sección oblonga decorada con joyas excelentes y valiosas, tan ricas que nadie ha visto iguales. La reina llevaba alrededor de la cintura un ceñidero de piel blanca hecho al estilo del que suelen llevar los hombres: [del] cual la faltriquera estaba decorada con un gran balaje del tamaño de una pelota pequeña, entre cinco resplandecientes diamantes y otras gemas del tamaño de una judía. Y el resto del cinturón estaba decorado con gran número de otras piedras preciosas. Llevaba al cuello un ostentoso collar de oro engastado enteramente con rosas blancas y rojas, cada rosa aderezada con una gran piedra preciosa. Además de esto, llevaba dos cintas suspendidas sobre cada uno de sus senos, engalanadas con grandes diamantes, balajes y otros rubíes, perlas y varias alhajas de gran valor en número de cien o más. Sobre el traje llevaba una capa de fino satén carmesí forrado de armiño, muy bello en apariencia y muy brillante. Estaba retirado hacia el lado izquierdo negligentemente. Llevaba la cabeza descubierta, excepto por una pequeña cofia en la parte trasera de la cabeza, y nada más. Verdaderamente como creo, y como oí decir entonces, estimo que aquel traje debía valer doscientos mil escudos de oro" 1 .

Esta lujosa descripción de la magnificencia de los reyes Fernando e Isabel pertenece al memorándum que Enrique VII de Inglaterra encargó con motivo del envío de una embajada destinada a España y Portugal, que partió de la corte Tudor en diciembre de 1488. Además del lujo descrito, y como si se tratara de un guiño a los embajadores, la reina eligió para la ocasión no solo una collar ostentoso sino que la joya encerraba un segundo mensaje, sus engastes de "rosas blancas y rojas" eran los emblemas de las casas Lancaster y York. Estos dos linajes se habían enfrentado durante años de la Guerra de la Dos Rosas a la que Enrique VII había puesto fin en 1485, y la reina Isabel descendía a través de su abuela materna, Catalina de Lancaster, de una de ellas. En honor de esta reina consorte de Castilla de origen inglés, Isabel y Fernando decidieron, en 1485, llamar a su última hija Catalina y en 1488, la embajada llegaba

1 J.M. BELLO LEÓN y B. HERNÁNDEZ PÉREZ, "Una embajada inglesa en la corte de los Reyes Católicos y su descripción en el diario de Roger Machado, Año 1489”, En la España Medieval, 26 (2003), pp. $189-190$. 
con la intención de firmar una alianza entre los tres reinos sellando el matrimonio de la infanta Catalina y el heredero de Enrique VII y príncipe de Gales, Arturo Tudor. No solo en esta primera ocasión la reina llevó una significativa joya sino que al día siguiente, el 15 de marzo, apareció con

"un paño ricamente tejido de oro, y sobre él, como antes, una capucha de terciopelo negro y sobre ella una cinta espolvoreada de oro batido y salpicada con rosas rojas y blancas de oro batido, cada rosa embellecida con espléndidas joyas. Llevaba alrededor del cuello un resplandeciente collar realzado con grandes rubíes y carbunclos, y de gran valor"'.

No sabemos si la reina eligió estas joyas consciente de lo significativo de su forma y color, pero en vista del cuidado que prestaba a sus apariciones públicas cabe pensar que quería mostrar su simpatía hacia la nueva dinastía reinante en Inglaterra, los Tudor, cuyo emblema era una rosa blanca sobre una roja, símbolo de unión de las casas de York y Lancaster.

Aún tomando la premisa de que la reina quisiera recalcar su conexión con la realeza inglesa, Isabel I era ante todo una castellana y así lo hizo ver a los embajadores al hacer su entrada en el torneo el día 22 del mismo mes. Apareció, detrás del rey, "a lomos de una fina mula y todo el arnés de la misma adornado con perlas y otras piedras preciosas" 3 . Esta imagen es muy similar a la que se produciría doce años más tarde en la entrada real en Londres de su hija la infanta Catalina, el 12 de noviembre de 1501, con motivo de la inminente celebración de su matrimonio con el príncipe Arturo. Enrique VII había supuesto que la joven entraría en litera según la costumbre inglesa ${ }^{4}$ pero, sin embargo, al cruzar el puente de Londres para adentrarse en la cuidad los londinenses pudieron verla

"sobre una gran mula, con una montura rica al estilo de España; el duque de York a su lado derecho y el legado de Roma a su mano izquierda. Su cuerpo estaba ricamente vestido, en el estilo de su país y sobre su cabeza un pequeño gorro, a la manera del de los cardenales, bellamente bordado, con un lazo de oro sobre este sombrero para estar oculto; su pelo suelto sobre sus hombros, que es de color pelirrojo claro, una especie de cofia entre su cabeza y su gorro de color clavel y esto estaba atado desde la mitad de su cabeza hacia arriba y así los hombres podían ver todo su pelo desde la mitad hacia abajo" $"$.

\footnotetext{
2 Ibid., p. 190.

3 Ibid., p. 192.

4 P.Y. HARDWICK (ed.), "Certain Notes taken out of the Entertainment of Katherine, Wife of Arthur, Princes of Wales, Oct. 1501)”, Miscellaneous State Papers, From 1501 to 1726, I, Londres, 1778, p. 9.

5 F. GROSE, T. ASTLE y E. JEFFERY (eds.), "Here begynneth the note and trewth of the moost goodly behavior in the receyt of the Ladie Kateryne, daughter unto Phardinand, the Kyng of Espayn, yowen in mariage to Prince Arthure, son and heir unto our noble Soferynge of Englond King Henry the VIIth, in the XVII yere of his reign", The Antiquarian Repertory: A Miscellaneous Assemblage of Topography, History, Biography, Customs, and Manners. Intended to Illustrate and Preserve Several Valuable Remains of Old Times, II, Londres, 1808, p. 278.
} 
El día de la boda en la catedral de San Pablo, el 14 de noviembre, la infanta Catalina volvía a poner la nota de exotismo que sorprendió al heraldo encargado de escribir el relato sobre los festejos, ya que llevaba

"sobre su cabeza un velo de seda blanca, con un borde de oro, perlas y piedras preciosas, siendo de una pulgada y media de ancho, que le cubría gran parte de su cara y de su cuerpo hasta la cintura, su vestido era muy largo, tanto en las mangas como en el cuerpo con muchos pliegos, muy parecido a las vestimentas de los hombres"6.

Vemos, por lo tanto, cómo en sus primeras apariciones en Inglaterra, Catalina continuaba vistiéndose como una infanta castellana gracias al rico ajuar que sus padres le proporcionaron ${ }^{7}$. Algunos de estos objetos pueden ser rastreados a través de la data de las cuentas de Alonso de Morales, tesorero de lo extraordinario de la reina Isabel ${ }^{8}$. Por ejemplo, hay varias "guarniciones de mula" que se prepararon para la "princesa de Gales" entre las que destacan las realizadas por Rodrigo de Alcázar, sumando la primera 141.248,5 maravedís y la otra "que se asentó sobre brocado raso morado", que costó $58.479,5$ maravedís ${ }^{9}$. El total que se había establecido para dotar a la infanta en los acuerdos ascendía a 200.000 escudos de oro; 15.000 tendrían que ser reunidos en diversas joyas y 15.000 más, en vasijas de oro, plata y plata dorada ${ }^{10}$. A pesar de que este impresionante ajuar llegó a Inglaterra en 1501, la prematura muerte de Arturo el 2 de abril de 1502 supuso la congelación de la entrega que no se efectuó hasta el segundo matrimonio de Catalina con el ya Enrique VIII en 1509.

El objeto de este artículo es poner de manifiesto la influencia de este ajuar en las artes suntuarias de la corte Tudor. Para ello, se tendrán en cuenta diversos inventarios de bienes del reinado de Enrique VIII donde aparecen los términos trabajo español o estilo español. También se podrá comprobar que desde su coronación en 1509 hasta su caída en desgracia a finales de la década de los años veinte del s. XVI, diversas joyas y objetos de orfebrería tenían entre sus decoraciones símbolos de la reina, el haz de flechas, el castillo y la granada, lo que nos podría dar pistas sobre su labor de patronazgo artístico en Inglaterra. Esto muestra cómo en la corte Tudor se asociaron

6 Ibid., p. 288.

7 E.L. CAHILL MARRÓN, "Arte y poder: negociaciones matrimoniales y festejos nupciales para el enlace entre Catalina Trastámara y Arturo Tudor”, UCrea, Santander, 2012. http://repositorio.unican.es/xmlui/ handle/10902/1490 (acceso 25/2/2014)

8 R. DE ANDRÉS, El último decenio del reinado de Isabel I a través de la tesorería de Alonso de Morales (1495-1504), Valladolid, 2004.

9 Ibid., entrada 3.778 .

10 Los objetos suntuarios también servían como avales. Cuando Fernando quiso hacer frente al segundo pago de la dote de su hija Catalina pidió un préstamo de 65.000 ducados a Agustín Italian. A cambio de que el genovés entregara el dinero en Londres a finales de febrero de 1508, el rey se comprometía a depositar en el monasterio de San Juan, extramuros de la villa de Burgos, un collar y una corona que había pertenecido a la reina Isabel la Católica. "La real cédula está firmada por el Rey y refrendada por el Cardenal de España, el secretario Juan López y el contado Antonio de Fonseca. Jorge de Vitoria en cumplimiento de lo ordenado por el Rey marchó de Burgos a Arévalo y recibió la corona y el collar. La entrega la efectuó María de Guebara en nombre de Juan Velázquez y en presencia de Juan de Osorio, Francisco de Mercado y Pedro de Encinas, escribano público de la villa en el mes de enero de 1508". D.M.M. MÁRMOL MARÍN, Joyas en las Colecciones Reales de Isabel la Católica a Felipe II, Madrid, 2001, p. 105. 
estos símbolos con su soberana y cómo algunos de ellos fueron mandados destruir por el rey en una campaña de damnatio memoriae que realizó junto a su amante Ana Bolena para borrar la memoria de una de las reinas consortes más influyentes de la historia de Inglaterra.

\section{El haz de flechas, el castillo y la granada: los símbolos de una reina}

La conquista de reino de Granada supuso uno de los mayores hitos de la historia europea del s. XV. El escudo del reino de Castilla fue modificado para incluir la homónima fruta, símbolo del triunfo de Isabel y Fernando sobre el último bastión musulmán en la Península Ibérica. Los reyes concedieron el privilegio a la última de sus hijas en abandonar la corte para contraer matrimonio el derecho a portar como emblema personal el símbolo de su triunfo, y en la Inglaterra Tudor se convirtió en imagen inconfundible de la reina Catalina. A pesar de ello, este no fue el único símbolo identificativo de la castellana, que también llevó consigo el haz de flechas y el castillo. Tras su coronación con Enrique, el 24 de junio de 1509, las decoraciones de la corte Tudor se llenaron de referencias a la nueva reina. En las cuentas reales de festejos cortesanos hay una partida el 28 de febrero de 1510, donde Robert Amadas, por orden del Earl de Essex, recibió un

"paquete de piezas de oro: en pares, marcados con la marca de Gibson con un haz de flechas y castillos, 590 piezas, 48 granadas de oro, 1.560 castillos y haces de flechas, 101 rosas y 108 granadas. Para los bordados, para cada traje, 240 piezas de haces de flechas y castillos. Montados en los dos mejores trajes, 480 piezas; en los dos siguientes, 360 piezas, en los dos últimos, 316 piezas: en las mejores medias blancas, 26 granadas de oro: en las medias verdes, 24 rosas de oro" $"$.

El 17 de marzo de 1510 existe otra entrada en las cuentas de festejos para

"una brida y un arnés, por orden del rey a Richard Gibson, para correr por la pista. También ordenada a Cumton, 575 haces de flechas de oro y 575 castillos de oro. Montados sobre el bocado y las mangas, 475 piezas; en el manto de la silla, 360 piezas; en el broont ${ }^{12} 130$; en el trene 60; en la jáquima y en las riendas anchas, 120 . Dadas por el rey a los señores de España que contemplaron la carrera del rey por la pista, 10 piezas. En total 1,150 piezas"13.

Ilustrativo de estas decoraciones relacionadas con la reina es el conocido como Westminster Tournament Roll, hoy en día en el Heralds Office de Londres, que se realizó con motivo del nacimiento del primogénito de Enrique y Catalina, el príncipe

11 J.S. BREWER (ed.), Letters and Papers, Foreign and Domestic, Henry VIII, Volume 2: 1515 1518, Londres, 1864, pp. 1490-1518. http://www.british-history.ac.uk/report.aspx?compid=90986 (acceso 25/2/2014).

12 Se han dejado en versión original aquellos términos que nos se corresponden con ningún término actual.

13 J.S. BREWER, op. cit., 1864, pp. 1490-1518. 
Enrique en día de Año Nuevo de 1511 (Fig. 1). En la imagen, que es un grabado del s. XIX del original, se puede apreciar cómo uno de los participantes en el torneo porta una granada y un castillo en las decoraciones de su montura y tanto en las tiendas como en las decoraciones de la montura de otro participante aparece la letra K, grafía inglesa de Catalina (Katharine o Katherine).

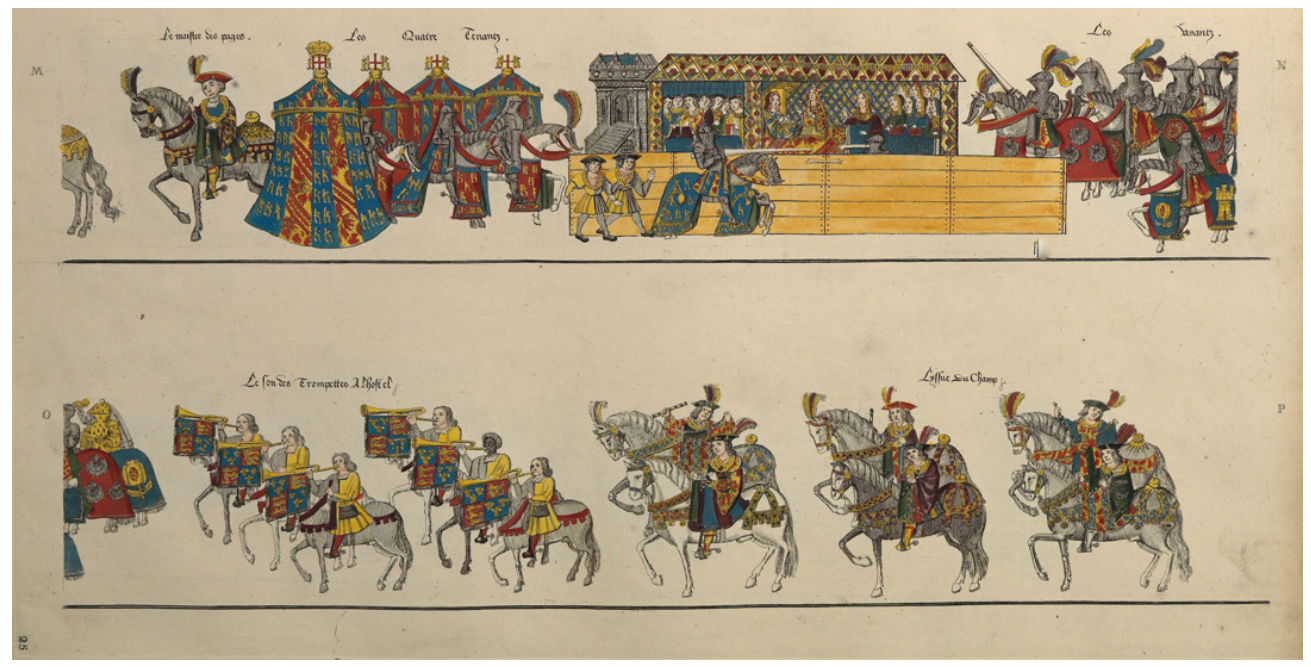

Fig. 1. Torneo celebrado con motivo del nacimiento del príncipe Enrique el día de Año Nuevo de 1511. Vetusta monumenta, 1, Londres, 1826.

El siguiente inventario de joyas que contiene los emblemas de la reina se realizó el 6 de octubre de 1519, donde aparece un "talabarte de oro, bien forjado, con rosas y granadas" además de un "broquel de plata dorada, con las armas de Inglaterra, rosas, castillos y granadas". Además de estas decoraciones también en este inventario aparece tanto "una escribanía de mesa decorada con las letras H y C", presumiblemente en relación a Enrique y Catalina como "una caja para peine de plata dorada, con $\mathrm{H}$ y K”, por lo que podríamos suponer que la primera de las piezas podría tener un origen castellano debido a utilizar la letra $\mathrm{C}$ y no la $\mathrm{K}^{14}$. Como destacó David Starkey, la reina Catalina forjó una duradera amistad con el duque de Buckingham, el noble de más alto rango tras el propio rey ${ }^{15}$. El 2 de septiembre de 1521 su capellán, Robert Gilbert, recibía noventa libras para reparar para la fiesta de Todos los Santos un broche "con una granada y una rosa" ${ }^{16}$. Otro de los cortesanos más influyentes, Thomas Wolsey, también contaba con piezas decoradas con los símbolos de la reina en varios de sus

14 J.S. BREWER (ed.), Letters and Papers, Foreign and Domestic, Henry VIII, Volume 3: 1519-1523, Londres, 1867, pp. 162-172. http://www.british-history.ac.uk/source.aspx?pubid=839 (acceso 25/2/2014).

15 D. STARKEY, Six Wives, The Queens of Henry VIII, Londres, 2003, p. 48.

16 J.S. BREWER, op. cit., 1867, pp. 485-516. 
inventarios. Como arzobispo de York, fueron encontrados en su castillo de Cawood ${ }^{17}$, varios "cuencos con tapa con rosas, granadas y pelícanos" entre las piezas de plata parcialmente dorada ${ }^{18}$. En su fundación personal de Oxford, el Cardinal's College -institución hoy conocida como Christ Church-, también aparecen piezas de este tipo en un inventario de bienes que se realizó en diciembre de 1530. Había "una liga con letras de oro, castillos y granadas, con un rubí en la hebilla, una turquesa en el colgante y una perla colgando" y también aparecen "veintidós corazones forjados con rosas y granadas". Entre las denominadas como "bolsas" están inventariadas "una de raso carmesí, con letras $\mathrm{H}$ y K bordadas" y "una de terciopelo negro, con una granada bordada y un talabarte". La última pieza con decoraciones castellanas es "una hebilla de plata dorada, con las armas de Inglaterra, rosas, castillos y granadas" 19 .

Es un inventario de joyas reales, realizado en 1532, el que nos vuelve a dar noticias de piezas relacionadas con la reina Catalina. La primera pieza es "una copa de oro" que tenía grabadas "rosas y granadas con una rosa roja y un rosa blanca en la tapa". También formaba parte de la partida "un candelero para un sise con una estela, una cadena, un par de apagavelas, grabadas en las parte de atrás con $\mathrm{H}$ y $\mathrm{K}$, una rosa y una granada", "un salero repujado con rosas y granadas, siendo el tapón un rastrillo" y "cucharas de oro, algunas adornadas con una piedra o una perla y algunas sin adornar, las divisas en ellas son $\mathrm{H} ; \mathrm{H}$ y K ; rosas y granadas; rosas, rastrillos y margaritas; rosas blancas y rojas; una corona imperial" ${ }^{20}$. Asimismo, se especifica que en otras copas aparece de nuevo la granada como parte de las decoraciones y están inventariados una serie de "saleros de plata dorada con tapas decorados con dragones, margaritas, rosas, rastrillos, granadas, San Juan Bautista, trabajo antiguo, rosas rojas y blancas y conchas de vieiras". Entre las imágenes de plata dorada y parcialmente doradas había

"un libro de los evangelios, una parte decorada con plata dorada y un crucifijo con María y Juan, las armas del rey con rosas rojas y granadas y el otro lado decorado con terciopelo púrpura, con cinco protuberancias de plata y de plata dorada" 21 .

En otro inventario de piezas de plata blanca aparecen veinte platos "parte de ellos marcados con la granada" 22 . Entre las piezas de oro que el rey mandó destruir el 13 de abril de 1533 había

"dieciocho copas con tapas con diferentes motivos, hojas de acebo y las armas del cardenal, de sierpes montadas con rubíes, diamantes y perlas, conchas, con el ramillete del cardenal bajo la almena de la tapa, las palabras Ecce Agnus Dei y sobre la tapa un

17 Los encargados de realizar dicho inventario fueron Enrique, earl de Northumberland, alcaide de de los East y Middle Marches, Walter Walch, uno de los caballero de la Cámara Privada y el nuevo abad St. Mary’s a las afueras de las murallas de York.

18 J.S. BREWER (ed.), Letters and Papers, Foreign and Domestic, Henry VIII, Volume 4: 1524-1530, Londres, 1875, pp. 3032-3052. http://www.british-history.ac.uk/source.aspx?pubid=841 (acceso 25/2/2014).

19 Ibid., pp. 3059-3078.

20 J. GAIRDNER (ed.), Letters and Papers, Foreign and Domestic, Henry VIII, Volume 5: 1531-1532, Londres, 1880, pp. 700-746. http://www.british-history.ac.uk/source.aspx?pubid=845 (acceso 25/2/2014).

21 Ibid., pp. 700-746.

22 Ibid., pp. 700-746. 
castillo con una montaña verde, rastrillos, lingotes, rosas y granadas; flores de lis y una media luna; rosas y uvas".

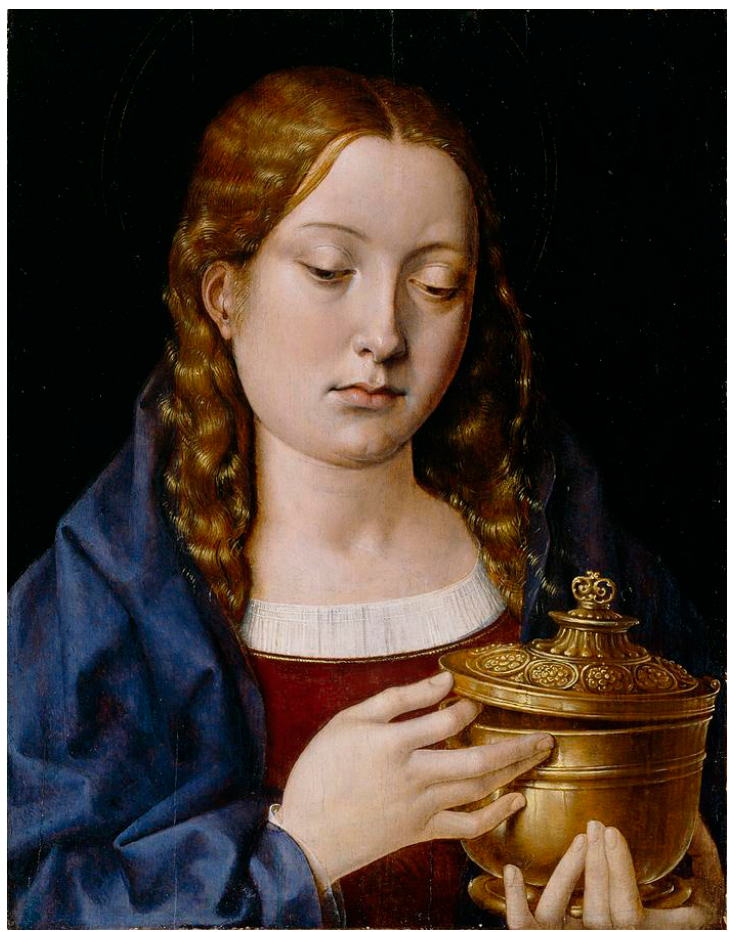

Fig. 2. Michel Sittow, Catalina de Aragón como la Magdalena, c. 1505, óleo sobre panel de roble (47 x 40,6 x 6,5 cm). Detroit Institute of Arts (EE.UU.).

También había "trece cálices con granadas, castillos y un nudo Stafford, R y C, flores de lis, granadas, un grifo" 23 . En una lista de piezas similar a la anterior con algunas piezas adicionales encontramos "tres layers de oro, chevarne wise con una rosa roja, rocky wise con una granada y grabada con rosas y flores de lis en rombos con una corona imperial" ${ }^{24}$ y en una lista de piezas reales de ese mismo mes aparecen "layers, doradas: con hojas de fresas, trabajo perchering, rosas y granadas". El 28 de octubre de 1536 aparece la última entrada relacionada con la granada en una cuenta de una lista de piezas de oro en el que aparece "un salero de oro y byrrall con una tapa que tiene rosas y una granada para el tapón, con un precio de tres libras, cuatro chelines y ocho peniques" 25 . Por todo ello vemos que era habitual en la orfebrería y

23 J. GAIRDNER (ed.), Letters and Papers, Foreign and Domestic, Henry VIII, Volume 6: 1533, Londres, 1882, pp. 151-170. http://www.british-history.ac.uk/source.aspx?pubid=846 (acceso 25/2/2014).

24 Ibid., pp. 151-170.

25 J. GAIRDNER (ed.), Letters and Papers, Foreign and Domestic, Henry VIII, Volume 11: JulyDecember 1536, Londres, 1888, pp. 349-378. http://www.british-history.ac.uk/source.aspx?pubid=852 (acceso 25/2/2014). 


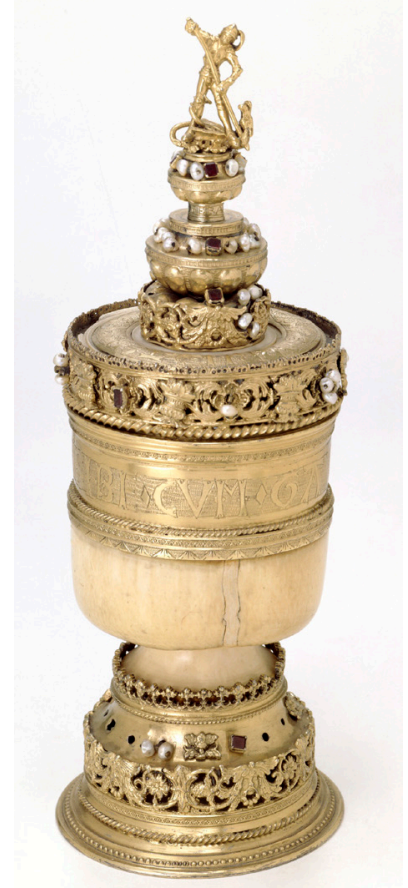

Fig. 3. The Howard Grace Cup, 1525-1526, cuenco de marfil de elefante pulido, con monturas de plata dorada, piedras preciosas, perlas y con marca de orfebre londinense. Museo Victoria \& Albert, Londres.

joyería en la primera parte del reinado de Enrique VIII entremezclar los símbolos castellanos con los propiamente Tudor.

Existe un retrato de Catalina de Aragón realizado por Michel Sittow circa 1505 que contiene una de estas piezas con decoraciones castellanas y Tudor, custodiado en el Detroit Institute of Arts (EE.UU.) (Fig. 2). En la tabla la infanta castellana aparece ataviada como María Magdalena y porta un pomo de perfumes. La pieza de oro tiene decoraciones repujadas en forma de flores que recuerdan a las rosas dobles Tudor sobre la tapa, que también contiene una granada coronando la misma. Teniendo en cuenta que la pieza de la imagen tiene una descripción muy similar al salero inventariado en 1536 es plausible que perteneciera a la colección personal de la reina Catalina. De confirmarse esta hipótesis, estaríamos ante un testimonio de suma importancia puesto que, como veremos más adelante, con el ascenso de la amante del rey, Ana Bolena, se inició un proceso de destrucción de la imagen de la reina Catalina en favor de la nueva favorita que supuso la desaparición de la mayor parte de los objetos que hemos descrito hasta el momento.

Tenemos otro ejemplo más de la importancia de la granada para conocer la labor de patronazgo artístico de la reina Catalina. En la colección del museo V\&A de Londres existe una copa conocida como The Howard Grace Cup (Fig. 3). Según los investiga- 
dores que han estudiado la pieza, parece ser que la copa fue un regalo de la reina a un cortesano. Se trata de la pieza más antigua conservada en Inglaterra con decoraciones renacentistas y tiene relación "con Catalina de Aragón, con la Orden de la Jarretera y sobre todo con el arzobispo asesinado, Thomas à Becket" ${ }^{26}$. En el año 1513 la reina recibió la "Sir Thomas' Cup" que le legó Sir Edward Howard en su testamento. Es probable que esta fuera la pieza de marfil que forma el corazón de la copa y que en 1525, año de la marca de orfebre, la reina mandara montar las decoraciones en las que destaca de nuevo la granada en la tapa y un San Jorge matando al dragón que conecta la copa directamente con la Orden de la Jarretera. Entre aquellos que fueron investidos caballeros en 1525 destaca la personalidad de William Fitzalan, XI Earl de Arundel, muy cercano tanto al rey como a la reina y cuya familia tuvo fuertes conexiones con los Howard, familia católica en cuyos inventarios aparece la pieza a partir de $1614^{27}$. Esta hipótesis se sostendría debido a que la pieza pudo ser escondida durante los años de destrucción de obras de arte que siguió a la Reforma Anglicana al permanecer en una colección privada de una familia que se mantuvo fiel a la Iglesia Católica. Futuras investigaciones tendrán que ahondar en el papel de la reina como patrona de esta pieza, clave para estudiar la llegada de las ideas italianizantes a la orfebrería Tudor.

\section{El trabajo español y el estilo español en los inventarios Tudor}

Aunque hayamos visto que tanto la granada, el haz de flechas y el castillo aparecen en las piezas suntuarias de varios inventarios Tudor, no quiere decir que fueran de fabricación castellana. En muchas ocasiones están combinadas con otros símbolos de la dinastía por lo que su manufactura es probablemente inglesa. Pero lo que sí se puede rastrear en los inventarios son las piezas en las que se especifica su diseño y origen como español. La primera referencia concreta volvemos a hallarla en las cuentas de festejos de Enrique VIII, concretamente el 6 de enero de 1516, día en que se dio instrucciones a Richard Gibson de parte de Sir William Cornish, maestro de los festejos, para preparar un castillo de madera en el salón del Rey a fin de representar la historia de Troilo, Pándaro, Calcas y Cresida donde Troilo portaba un ceñidor de estilo español ${ }^{28}$.

Los inventarios de piezas de orfebrería y joyas vuelven a ser las fuentes en las que abundan las referencias. El 6 de octubre de 1519 en un inventario de joyas reales pertenecientes al rey y que atesoraba Sir William Compton había tanto un talabarte de "trabajo español, con 16 bellos balajes y 44 perlas", como "una cadena, de trabajo español, esmaltada de blanco y rojo; con un balaje colgando de ella" o "una bolsa española con borlas de oro" ${ }^{29}$. En otro inventario real, cuyas piezas habían llegado

26 P. GLANVILLE, “The Howard Grace Cup”, History Today, 44 (10) (1994), p. 41.

27 Ibid., p. 43.

28 Personaje homérico hijo de Príamo participante en la Guerra de Troya. J.S. BREWER, op. cit., 1864, pp. 1490-1518.

29 J.S. BREWER, op. cit., 1867, pp. 162-172. 
a manos del rey a través de una confiscación de la viuda Lady Agnes Hungerford en febrero de 1523, acusada de asesinato, había ocho partlets ${ }^{30}$ de Chipre, decoradas con oro y trabajo español ${ }^{31}$. De nuevo en 1526, concretamente el 18 de enero, entre las joyas entregadas a Master Henry Norres, en la manor de Eltham pertenecientes al rey, había "una cadena de trabajo español, roja y blanca, con un gran balaje" 32 . Ese mismo día se entregó a Robert Amadas, "un collar de trabajo español con dieciséis bellos balajes" 33 .

Pero de nuevo, no solo el rey contaba con estas piezas. El 26 de junio de 1527 se realizó un inventario de bienes en la casa de Thomas Cromwell; entre las piezas podemos destacar que había "un talabarte de seda roja español" que estaba en la Cámara de la Priora y en la Cámara Nueva también apareció "una daga española con contera de plata" 34 . También en el ya citado inventario del Cardinal's College realizado en 1530 se encontró "una cadena de trabajo español, esmaltada de blanco y rojo, con un gran balaje", "un corazón de trabajo español con san Pedro de Milán, con seis diamantes", un aderezo para la cabeza descrito como "un aparato con cuatro balajes cuadrados, sobre una rosa blanca y roja, con ramas de perlas, un león y otras piezas rotas de adorno y trabajo español" y "dos monedas españolas" ${ }^{35}$. En otra lista, a continuación, que contiene los mismos artículos pero en distinto orden se añadían algunas entradas más como "un pomo de perfumes y una tableta, de trabajo español"

Es la muerte de uno de estos encargados de custodiar las joyas y posesiones reales, Robert, lo que aporta más noticias sobre estas piezas, concretamente al inventariar una serie de joyas reales que pasarían al cuidado de Thomas Cromwell ${ }^{37}$. Entre las diversas joyas había

"un collar de trabajo español, con quince bellos balajes, seis diamantes apuntados, dos diamantes, dos grandes diamantes talla baguette cuadrada, otro diamante cuadrado talla baguette, otro diamante en forma de corazón, un diamante talla baguette hexagonal, un gran diamante triangular, un gran diamante romboidal y el Gran Espejo".

Había dos collares más de "trabajo español, esmaltados con imaginería y flores, con un haz de flechas montado sobre la base" 38 , "un pax o tabernáculo de plata dorada, de trabajo español, con Nuestra Señora de la Piedad", "una copa con pie, do-

\footnotetext{
30 Un partlet era una camisa típica en el s. XVI que tenía cosido un borde. http://www.merriam-webster. com/dictionary/partlet (acceso 25/2/2014)

31 J. S. BREWER, op. cit., 1867, pp. 1188-1205.

32 J. S. BREWER, op. cit., 1875, pp. 831-849.

33 Ibid., pp. 831-849.

34 Ibid., pp. 1447-1465.

35 Ibid., pp. 3059-3078.

36 Ibid., pp. 3059-3078.

37 El informe está firmado por Sir Thomas Awdeley, guardián del Gran Sello, Sir William Pawlett, interventor de la Casa del Rey, Sir William Kyngeston, Sir Brian Tuke y Sir John Daunce, comisarios nombrados por cartas con firma del consejo privado, y está fechado en Eltham, el 2 de junio de 1532 . En el documento constaba que los firmantes certificaban que en el día 24 que en ciertos días de junio y julio de ese mismo año las piezas de orfebrería y las joyas, fueron examinadas y pesadas.
}

38 J.S. BREWER, op. cit., 1867, pp. 167-172. 
rada, de estilo español, repujada con hojas de acebo, con una torre en el tapón de la tapa", "dos jarras grandes doradas y repujadas con las armas del rey en el medio, de estilo español", "platos para especias de plata dorada y parcialmente dorados entre los que había algunos con flores de agua de manufactura española", "una escribanía de trabajo español dorada, con una caja de plata para la tinta", "cuencos cubiertos y cuencos sin cubrir con aguamaniles de plata dorada", "un par de buenos cuencos doblemente dorados, repujados con estilo español, uno con una corona y las armas de Inglaterra y España", "otro con las armas de Inglaterra y España" y "un bello layer con tapas doradas, del estilo español, bien forjado con ramas, nidos y pájaros" ${ }^{39}$.

En una lista de piezas reales de abril de 1533 había "dos candeleros dorados de trabajo español" y entre las denominadas como "piezas para el banquete del rey" estaban inventariadas "dos tinajas cubiertas de trabajo español" 40 " "siete copas doradas de estilo español y de Almain; una dada por el abad de St. Mary" y "tres layers de trabajo español, de las piezas de la reina". Ese mismo mes, con fecha del 13 de abril, existe una orden del rey para destruir una serie de piezas entre las que había "dos platos para especias, rotos por el borde, de estilo español que tenían imaginería", "dos platos para especias con flores de agua repujadas, de estilo español" o "el plato dorado de limosnas de la reina"41. La última de las referencia, también en abril de 1533, se corresponde con un inventario de las piezas de orfebrería que seguía poseyendo la reina Catalina entre las que había "un crucifijo de trabajo español sobre un pie, de sus propias piezas" ${ }^{42}$, por lo que vemos que la reina fue despojada paulatinamente de todos aquellos objetos que sus padres le habían proporcionado como dote matrimonial pasando a diversas colecciones en Inglaterra.

\section{Las artes suntuarias como símbolo de estatus de la reina: el proceso de damnatio memoriae}

Retomando el inventario de abril de 1533 donde el rey ordenaba destruir algunas piezas, algunas de ellas de trabajo español, podemos comprender algunas de las razones que llevaron al monarca a querer destruir la imagen de su primera esposa. Es muy representativo que entre estas piezas estuviera el "plato de limosnas de la reina" que era una pieza clave del estatus de la soberana. La caridad era uno de los principales rasgos que se atribuía a las buenas reinas y en el caso de Catalina de Aragón diversos autores han señalado que su popularidad tanto en la corte Tudor como entre los vasallos del rey se debió a que se comportó siempre como una soberana ejemplar, dando limosnas frecuentemente ${ }^{43}$. Esto acarreó muchos problemas cuando Enrique VIII decidió iniciar un proceso de nulidad matrimonial al que Catalina se negó en

39 Ibid., pp. 167-172.

40 J. GAIRDNER, op. cit., 1882, pp. 151-170.

41 Ibid., pp. 151-170.

42 Ibid., pp. 151-170.

43 G. MATTINGLY, Catherine of Aragon, Boston, 1941, pp. 178-180; A. FRASER, The Six Wives of Henry VIII, Londres, 1993, pp. 99-100. 
rotundidad. Y dos son los episodios clave que nos ayudan a comprender cómo estos objetos suntuarios cumplían un papel fundamental en las relaciones entre los miembros de la corte. También nos ilustran sobre la consideración que la reina Catalina tenía sobre los objetos suntuarios y cómo comprendía su valor como símbolos de su condición real.

El primero de los episodios tuvo lugar durante el reparto de regalos realizado el día de Año Nuevo de 1532 y tenemos constancia de él a través del embajador imperial, Eustace Chapuys:

"La reina había sido vetada de escribir cartas o mensaje al rey y aún así deseando cumplir con su deber para con él, hizo presentarle el día de Año Nuevo, a través de un caballero de la cámara, una copa de oro de gran valor y singular calidad siendo el regalo ofrecido de la manera más humilde y apropiada para la ocasión. El rey, sin embargo, no sólo rechazó aceptar el regalo sino que parecía muy enfadado en principio con el caballero que había asumido traerlo. Pero parece que dos o tres horas más tarde el rey mismo deseaba ver la copa otra vez, alabó mucho su forma y calidad y temiendo que el caballero de su cámara que lo había recibido del mensajero de la reina lo llevara de vuelta inmediatamente -en cuyo caso la reina podría haberlo presentado delante de los cortesanos (devant tout le monde), en cuyo caso él (el rey) no podría a bien rechazar su aceptación- ordenó al caballero no devolver al caballero la copa hasta la tarde, cosa que fue realizada y entonces fue devuelto a la reina. El rey, además, no le envió regalo de Año Nuevo en esta ocasión y, he oído, ha prohibido a los miembros del Consejo Privado, así como a los caballeros de su cámara y otro a cumplir con esta dicha costumbre" 44 .

De nuevo gracias al embajador de Carlos $\mathrm{V}$ tenemos constancia de un segundo episodio en el que Enrique demostraría su cambio de favor hacia Ana Bolena y la caída en desgracia de la reina Catalina. El 1 de octubre de 1532, y ante la insistencia de su amante, Enrique VIII pidió a Catalina que entregara las joyas reales. Ante tal petición, la reina había declarado que estaba "en contra de su conciencia dar sus joyas a una persona que es el escándalo de la Cristiandad y una deshonra al rey" ${ }^{45}$. Finalmente tuvo que capitular ante la orden directa de Enrique, dos días más tarde, como podemos ver por un registro de un libro de joyas entregadas por el rey a Cromwell, para dar a Cornelis Hayes, orfebre, ciertas piezas para ser alteradas. Entre ellas había "14 esmeraldas, 18 rubíes, 63 diamantes, 2 balajes y 418 perlas montadas en varias joyas, estando a parte 20 rubíes y 2 diamantes reservados para la señora marquesa (Ana Bolena)". El 6 de septiembre aparecía otra lista donde había "un tabernáculo de oro montado sobre un cojín de oro, con una imagen de Nuestra Señora coronada y su hijo en el regazo, con un dosel. El tabernáculo también contiene imágenes de ángeles, San Jorge y el Dragón, San Juan Bautista, Santa Catalina, escritorios de la Ascensión y la Resurrección de Nuestro Señor y otras figuras, todas descritas. Las piedras que

44 P. GAYANGOS (ed.), "Spain: January 1532, 1-10”, Calendar of State Papers, Spain, Volume 4 Part 2 : 1531-1533, Londres, 1882, pp. 352-362. http://www.british-history.ac.uk/report.aspx?compid=87756 (acceso 25/2/2014).

45 J. GAIRDNER, op. cit., 1880, pp. 589-599. 
contiene son las siguientes: 24 diamantes, 9 rubíes, 18 esmeraldas, 8 balajes, 4 zafiros, 2 granates, 1 jacinto y 126 perlas. Junto al tabernáculo también se hacía entrega de un talabarte de oro, un engaste y una imagen de San Jorge con 14 balajes, una esmeralda y 134 perlas" ${ }^{46}$.

Enrique mandó destruir cualquier representación que contuviera granadas, por lo que los testimonios que han sobrevivido son pruebas de la resistencia de algunos cortesanos a destruir la memoria de su querida reina. Catalina se mantuvo firme en su convicción de que continuaba siendo la legítima reina de Inglaterra y en una misiva que escribió poco antes de morir en enero de 1536 pedía a su esposo que cumpliera con su última voluntad. La ley inglesa no permitía a las mujeres casadas testar, por lo que la apelación al monarca fue el único mecanismo para que los pocos bienes que aún le quedaban fueran a parar a las personas que todavía contaban con su confianza. En la carta pedía que "le dejara hacer uso de los bienes que ella poseía de él en oro y plata y el dinero pagadero a su persona en tiempo pasado", le pedía asimismo que le entregara a su hija "el collar de oro que traje de España" y "que a mi orfebre se le pague el sueldo del año en curso y todo lo se le debe aparte" 47 . Por lo que la última pieza que Catalina todavía conservaba de su pasado en Castilla debía ser entregada a su hija, María, quien años más tarde se convertiría en la primera reina de Inglaterra por derecho propio. Durante su breve reinado, María I procuró, pese al devastador proceso de damnatio memoriae de la imagen materna provocado por su padre, recuperar la memoria de la soberana de origen castellano asumiendo como uno de sus emblemas personales la granada, símbolo del poder de los reyes Fernando e Isabel.

46 Ibid., pp. 589-599.

47 J. GAIRDNER (ed.), Letters and Papers, Foreign and Domestic, Henry VIII, Volume 10: January-June 1536, Londres, 1887, pp. 12-26. http://www.british-history.ac.uk/source.aspx?pubid=851 (acceso 25/2/2014). 